\title{
Relatos de mães sobre transformações familiares em três gerações
}

\author{
Ciomara Ribeiro Silva Benincá \\ Universidade de Passo Fundo (RS) \\ William B. Gomes \\ Universidade Federal do Rio Grande do Sul
}

\begin{abstract}
Resumo
Examinou-se um conjunto de descrições e entendimentos de mudanças em idéias e comportamentos familiares através de três gerações. As informantes foram doze mães provenientes de quatro diferentes famílias, seguindo a linearidade geracional de avó, mãe e neta. Todas elas residiam na região de Passo Fundo - RS. Utilizando-se uma análise qualitativa baseada na teoria fenomenológica, interpretou-se as continuidades e descontinuidades de comportamentos e idéias em duas perspectivas: 1) redimensionamento no poder do pai e da mãe e na coesão familiar; e 2) transformação da identidade coletiva em identidade individual, com a ampliação do espaço para a realização pessoal. Continuidades mostraram-se associadas a princípios ideais como a ética familiar. Em contraste, descontinuidades aconteceram de acordo com pressões contextuais nos aspectos práticos da vida familiar.

Palavras-chave: Padrões-

transgeracionais, Relaçõesintergeracionais, Fenomenologia.
\end{abstract}

\footnotetext{
Abstract

Mothers' reports about family transformation across three generations. Examined a set of mothers' descriptions and understandings of family values and behaviors across three
} 
Key words: Transgenerationalpatterns, Intergenerationalrelations, Phenomenology generations. The informants were twelve mothers, from four different families, following a generational linearity of grandmother, mother and granddaughter. All of them were residents in the area of Passo Fundo/RS. By using a qualitative analysis based on a phenomenological theory, the continuities and discontinuities of behavior and ideas were interpreted in two perspectives: 1) new arrangement in the power of father and mother and in the family cohesion and 2) changing from collective to personal identity with an increasing in the space for self realization. Continuities were related to general principles as family ethics. In contrast, discontinuities happened according to contextual pressures in the practical aspects of family life.

$\mathrm{A}$

família é um organismo mutável que transforma e é transformada pela sociedade. É a família que, pela adoção de certas regras comunicativas e conceituais, abre espaço para as mudanças sociais. Em contrapartida, a organicidade familiar se redimensiona por conta das pressões sociais originárias dessas mudanças (Prado, 1982; Romanelli, 1988). Configura-se, então, um movimento permanente de oposição entre valores e regras da herança familiar, e valores e regras da urgência do tempo presente.

A dinâmica relacional da família no processo de socialização submete-se, ao mesmo tempo, às leis internas e externas. As leis internas são regras de organização familiar e a leis externas são decorrências do sistema social vigente que contextualiza a organização familiar (Samara, 1986). Nesse processo bidirecional de influências, os pais preocupam-se com a transmissão dos seus valores como forma de projetar sentido e justificação às suas vidas. Os filhos, ao contrário, querem estabilizar seus próprios valores recorrendo a estratégias compatíveis com as modernidades tecnológicas, demográficas e políticas. Localiza-se aí o drama da sucessão contínua em família: a diversidade nos valores e comportamentos; e a luta entre gerações pela estabiliza- 
ção da identidade (Aldous, 1978; Bengtson \& Kuypers, 1971; Fisher \& Johnson, 1990).

O processo sucessivo, considerando tanto a sociedade mais ampla quanto a família restrita, envolve gerações diversas com características peculiares que as identificam como diferentes da anterior e, provavelmente, da seguinte. Contudo, a linearidade familiar mantém-se de forma incontestável através dos tempos. Isto se dá pelo consenso entre os grupos geracionais sucessivos na mutualidade das experiências, da assistência, das obrigações, das expectativas e do afeto.

A perspectiva transgeracional destaca-se frente a situações de mudança social para evidenciar os movimentos de oposição e as alternativas de estabilização em uma nova cultura. Cultura refere-se à bagagem de conteúdos básicos e habilidades sociais de efeito diretivo e mutante, transmitida formal ou informalmente dos mais velhos para os mais novos por processos de simbolização. A herança cultural, portanto, funciona como incremento da informação biológica de preservação da espécie. Amplia-se através da renovação de práticas sociais e do acréscimo progressivo de novas descobertas (Tolor, 1976).

A partir do enfoque transgeracional é possível descrever a tendência de um grupo aparecer na história como força política ativa, gerando alternativas intelectuais e organizacionais para a visão de mundo. Nesse enfoque, o critério para a mudança geracional é a urgência de novas habilidades ou de novos valores e estilos de vida. Por conseguinte, a descontinuidade geracional caracteriza-se pela substituição de antigos padrões de comportamento dos diversos grupos de idade no decorrer do tempo (Bengtson, 1996). A continuidade, por outro lado, caracteriza-se pela reedição de comportamentos através do processo de combinação de expectativas e atribuições, implícitas ou explícitas, que se transformaram em padrões de conduta. Nestes padrões, destacam-se aqueles comportamentos específicos e modelos sociais reconhecidamente eficazes (Williamson \& Bray, 1991).

O termo geração, neste trabalho, refere-se ao fenômeno de pessoas com idades similares que vivenciam um problema histórico concreto de experiências comuns com o sistema político, social, econômico e cultural (Laufer \& Bengtson, 1974). De uma perspectiva psicológica, o 
termo geração refere-se a expressão coletiva e o reflexo de estágios de mudança no desenvolvimento da personalidade, no comportamento e nos valores, em um grupo etário num período de tempo específico (Guardo, 1982).

Historicamente, o conceito de geração passou a ser utilizado de forma especial no final da década de sessenta para explicar o papel diferenciado de cada estrato de idade como força ativa no processo de mudança social. Nessa época, as diferenças entre gerações tornaram-se objeto de estudo dos pesquisadores interessados na turbulência dos movimentos estudantis (Jenning \& Niemi, 1968).

Atualmente, as relações intergeracionais são discutidas por cientistas americanos interessados no Generation Gap (Thomas, 1974). Eles preocupam-se com as semelhanças e diferenças de valores e comportamentos, entre as gerações. A principal controvérsia é a existência em maior ou menor grau do distanciamento ( gap) entre os grupos de idade. De um lado, defende-se a descontinuidade entre gerações e questiona-se o poder da herança cultural (Cashmore \& Goodnow, 1985). Do outro, defende-se a continuidade geracional, alegando que a descontinuidade é um produto da mídia, divulgado com base na rejeição drástica de minorias radicais (Acock \& Bengtson, 1980). Há, também, uma posição moderada que reconhece tanto as diversidades provocadas pela modernidade, quanto as semelhanças geracionais promovidas pela herança familiar (Rosenthal, 1984).

No Brasil, as pesquisas concentram-se na questão da descontinuidade entre gerações no contexto de um processo de mudança social acelerada, principalmente nas camadas médias. A questão foi muito discutida nos finais dos anos oitenta (Almeida, 1987; Figueira, 1987, 1991; Lins de Barros, 1987; Nicolaci-da-Costa, 1987, 1988; Romanelli, 1988; Velho, 1981, 1989). Estes trabalhos preocupam-se com três aspectos: direção das mudanças, significado da discriminação entre o moderno e o arcaico, e o impacto da modernização na estrutura das subjetividades (Biasoli Alves, Caldana \& Dias da Silva 1988). Na tradição psicanalítica foram realizados estudos de caso sobre o funcionamento dinâmico intergeracional na reedição de comportamentos dos antepassados (Andolfi, 1989; Ferro-Bucher, 1986). 
Alguns trabalhos brasileiros sobre relações intergeracionais merecem destaque. Dias da Silva e Biasoli Alves (1987a, 1987b), por exemplo, entrevistaram mães de três gerações a respeito das alterações nos fundamentos das práticas educativas em 50 anos. Os resultados apontam para importantes mudanças na família contemporânea em direção à "des-repressão", tanto do comportamento quanto das subjetividades. Sob o mesmo enfoque, o trabalho de Lins de Barros (1987) com depoimentos da geração mais antiga, evidencia mudanças e permanências de padrões sociais e culturais, bem como a diversidade de representações sobre família pela intersecção dos sistemas simbólicos de cada geração em particular. Ainda, a pesquisa de Almeida (1987) contrastrou grupos de mães das décadas de 50 e 80, e demarcou as representações destas mulheres sobre a maternidade. Estas mães definiram suas representações como modernas e libertadoras enquanto representaram as posições de suas genitoras como arcaicas e tradicionais.

Os estudos sobre a família brasileira destacam quatro fatores de mudança geracional: 1) as exigências econômicas decorrentes da intensificação industrial e urbana; 2) a inserção profissional da mulher; 3) a distribuição social do conhecimento pela transformação súbita nos meios de comunicação de massa; e 4) a quebra do poder integrador das relações de parentesco com o enfraquecimento da família nuclear (Figueira, 1987; Nicolaci-da-Costa, 1987, 1988; Romanelli, 1988; Velho, 1981, 1989). Tais mudanças cristalizaram-se, principalmente, a partir da década de sessenta.

Até meados de 1960 a família tradicional, tida como estável, fornecia o código moral em posições e papéis segregados e complementares de pai, mãe e filhos, bem como o permitido e o proibido para os ocupantes de cada posição. Tais regras organizavam a experiência de socialização do sujeito, que internalizava um código moral rígido e bem demarcado. Porém, a família subitamente transformou-se, acompanhando a modernização da sociedade. Essa transformação rápida deixou a família incerta quanto às regras a seguir (Romanelli, 1988; Velho, 1981, 1989). O questionamento e o redimensionamento das relações afetivas e sexuais, das idéias e comportamentos, têm como conse- 
qüência um novo conjunto de representações acerca do funcionamento e estrutura familiar, principalmente entre gerações diferentes.

Comparações transgeracionais vem sendo utilizados em uma grande diversidade de pesquisas. São exemplos recentes estudos em estabilidade e transmissão de apego (Benoit \& Parker, 1994), distúrbios de apego e estilo afetivo negativo (Diamond \& Doane, 1994), limites de intrusão na relação mãe e filha (Jacobvitz, Morgan, Kretchman \& Morgan, 1991) transmissão de atitudes e crenças (Clebone \& Taylor, 1992), transmissão de controle social (Rogers, Parcel \& Menaghn, 1991), transmissão de disciplina e comportamentos convencionais (Covell, Grusec \& King, 1995), agressão (Doumas, Margolin \& John, 1994) e continuidade e mudança na vida rural (Elder, King \& Conger, 1996). Estes trabalhos procedem de diferentes países e seus resultados circunscrevem-se aos limites das metodologias usadas. Leiden (1992) revisou estudos sobre transmissão transgeracional de habilidades em criar filhos. Em suas conclusões mostrou-se desapontado com os resultados de estudos que utilizavam questionários mas viu como promissores propostas de estudos observacionais e qualitativos.

Este estudo interessa-se, particularmente, pela perspectiva transgeracional no processo de sucessão geracional. A pergunta de pesquisa é a seguinte: Como gerações diferentes dentro de um mesmo grupo familiar identificam similaridades e variações entre os valores e comportamentos de sua geração e os valores e comportamentos que podem ser relacionados à história familiar? Espera-se, também, reunir descrições que permitam levantar algumas interpretações possíveis sobre permutas intergeracionais e intrageracionais.

\section{Método}

\section{Informantes}

Foram entrevistadas doze mães de classe média pertencentes a quatro famílias residentes na cidade ou região de Passo Fundo/RS, respeitando-se a linearidade trigeracional (avó/filha/neta). A mãe é considerada o principal agente de socialização primária e aglutinação 
familiar (Acock \& Bengtson, 1980; Aldous, 1978; Cashmore \& Goodnow, 1985; Lins de Barros, 1987, Tolor, 1976). A escolha pela classe média apóia-se no argumento de que é o estrato social mais exposto ao processo de inovação sócio-tecnológica que produz novas necessidades, habilidades e exemplos de organização social (Almeida, 1987; Figueira, 1987; Laufer \& Bengtson, 1974; Lins de Barros, 1987; Nicolaci-da-Costa, 1988; Romanelli, 1988; Velho, 1989).

O critério para composição do grupo de informantes foi o da seleção deliberada (Morse, 1994). Assim, a intencionalidade e conveniência do pesquisador foram os principais critérios de escolha das unidades representativas. A técnica justifica-se pela dificuldade em encontrar o tipo de população alvo da pesquisa (famílias que contemplam três gerações de mães) que é limitada em termos de tempo, energia e recursos econômicos. Dessa forma, as primeiras famílias foram indicados por pessoas das relações dos pesquisadores. Essas famílias indicaram outras e assim por diante.

Quanto à idade, a média na primeira geração foi de 77 anos. Eram mulheres procedentes de famílias com uma prole média de 13 filhos, tendo, em média, quatro filhos. Na segunda geração, a média de idade foi de 55 anos e tinha, em média, três filhos. Na terceira geração, a média de idade foi de 32 anos, tinha em média dois filhos, com idades variando entre quatro e 14 anos.

\section{Instrumento/Procedimento}

$\mathrm{O}$ instrumento de pesquisa foi uma entrevista semi-estruturada e de seqüência flexível (Anexo A). Os tópicos exploravam as experiências pessoais, familiares e geracionais da informante, aproximando-se muito de um estudo de história de vida. O princípio fundamental era estabelecer uma relação amistosa entre entrevistador e entrevistada, na qual a entrevistada expressasse seu entendimento em suas próprias palavras. Porém, conservou-se critérios para comparação das respostas, mantendo-se presente a necessidade de verificar os principais itens do roteiro, o que não implicou em desprezar outros tópicos que porventura fossem abordados pelas informantes. Conservou-se, então, a particularidade de cada relato mantendo suas prioridades e ênfases. 
As entrevistas foram gravadas em audioteipes e posteriormente transcritas para análise. Tal procedimento vem ao encontro da proposta dos métodos de avaliação qualitativa (Patton, 1990) de entender a perspectiva do entrevistado através da "captação" (do latim "capta" em contraste com "data" dos métodos quantitativos) de suas palavras e sentidos (Lanigan, 1988). A duração média das entrevistas foi de uma hora e meia. As entrevistas foram realizadas na residência dos entrevistados. No entanto, algumas representantes de terceira geração foram entrevistados nos locais de trabalho.

A ordem das entrevistas na tríade geracional também foi diversificada, possibilitando diferentes organizações seqüenciais de depoimentos. Tal diversidade aconteceu intencionalmente, no sentido de variar a localidade da escuta do entrevistador, evitando interferências de uma sucessão rígida de entrevistas. Da mesma forma, o primeiro contato, responsável por possibilitar a realização das entrevistas, variou nas quatro famílias.

\section{Critérios de Interpretação e Validação}

Os depoimentos obtidos através das entrevistas foram analisados e interpretados por critérios de pesquisa qualitativa ou descritiva, seguindo-se, para tanto, a tradição da fenomenologia (Giorgi, 1985; Gomes, 1987; Lanigan 1988). O termo fenomenologia é usado, neste estudo, no sentido definido por Spiegelberg (1982), isto é, o retorno aos recursos primários da intuição direta, para através do exame de suas estruturas essenciais clarificar problemas e concepções. Os depoimentos colhidos das entrevistas constituíram-se numa descrição das histórias familiares. Tais histórias, lidas atentamente para definição de unidades de sentido, foram reduzidas a categorias temáticas; na verdade, uma interpretação. Por fim, a significação emergente da interpretação temática passou a ser uma descrição dos relatos apresentados pelas informantes. A seguir, contrastou-se a percepção das informantes com a percepção da literatura, produzindo-se uma nova redução, que foi interpretada em termos das presenças e ausências entre as duas perspectivas. Dessa discussão, produziu-se uma interpretação enquanto proposta compreensiva dos pesquisadores. 
A veracidade do método qualitativo depende do cuidado descritivo e da sensibilidade interpretativa do pesquisador. A interpretação, enquanto reflexão da descrição, deve englobar todas as complexidades e sutilezas da situação nas suas diferentes estruturas e variações temáticas, e apresentar-se como significação possível e elucidativa. Tais cuidados trazem para a interpretação a credibilidade enquanto discussão pertinente e necessária sobre o tema em foco. Observe-se, todavia, que a credibilidade dos tomados (para contrastar com os achados dos métodos quantitativos) não está na busca de similaridades (o propriamente generalizável), mas de aproximações estruturais que esclarecerão e contextualizarão o propriamente generalizável. A interpretação qualitativa poderá conter um potencial de transferibilidade, ou seja, sua identificação descritiva com outras comparações intergeracionais em contextos próximos (Altheide \& Johnson, 1994).

A apresentação das percepções geracionais obedecerá à seqüência dos três passos fenomenológicos. O primeiro apresenta e descreve os trios geracionais que participaram da pesquisa, no contexto da grande família. O segundo reduz o foco para demarcar as mudanças e permanências na estrutura familiar, na sucessão geracional. O terceiro, articula e interpreta as demarcações indicadas na redução para interpretá-las no contexto da perspectiva dos participantes, dos pesquisadores e da literatura.

\section{Descrição Fenomenológica}

A leitura fenomenológica das entrevistas manteve sempre em tensão o relato da informante, enquanto uma expressão vivencial e o entendimento do pesquisador, enquanto uma percepção de um dado relato. Com isto, atendeu-se à exigência fenomenológica do retorno à experiência original, no caso, o confronto entre a expressão da informante e a percepção do pesquisador. Essa mesma condição relacional, em seu reverso, pode ser entendida tanto como a expressão do pesquisador, enquanto alguém que pergunta, e a percepção da informante, enquanto alguém que responde. $\mathrm{O}$ diálogo entre entrevistador e entrevistado, este entendimento possível (intersubjetividade) que se 
estabelece entre dois comunicantes, constituiu-se numa narrativa, que é uma experiência vivida na qual fatos e interpretações, idéias e valores, subjetividade e objetividade, apresentam-se em seu estado bruto de totalidade e inseparabilidade. Assim, a construção de um sentido, que é o existir ou estar-no-mundo em uma situação familiar diferenciada por gerações, foi obtida através das três reflexões fenomenológicas (descrição, redução e interpretação), cada uma destas reflexões incluindo as demais, por estarem interligadas através de um sinergismo progressivo. Trabalha-se, então, com uma realidade na qual qualquer começo ou qualquer fim é sempre uma artificialidade (Lanigan, 1988).

A descrição foi composta por recortes das entrevistas. A seleção desses excertos não implica, contudo, no desprezo das partes restantes, mas sim na interpretação do pesquisador de que se constituíram em sínteses reveladoras dos aspectos considerados (Ver Exemplo 1). Sendo assim, o texto originário foi organizado em unidades de sentido tendo como eixo central as modificações da estrutura familiar na sucessão geracional. Contemplou-se, então, um sentido geral tomado (capta) das quatro famílias, deixando de lado a especificidade de cada grupo familiar. No Exemplo 1, as palavras sublinhadas indicam as partes tomadas pelos pesquisadores como frases revelatórias, isto é, frases que apresentavam de modo sintético (julgamento dos pesquisadores) as perspectivas das informantes.

Exemplo 1 - Critério de Seleção de Frases para Composição e Exemplificação de Categorias e Interpretações

Pergunta: E a sua mãe, como era?

Resposta: Ela era muito rígida, mas era de muito préstimo. Ela plantava, criava vaca, criava porco, criava galinha, criava tudo. Ela plantava melancia, coisa, coisa, e vendia; ia com a carroça e vendia e trazia pra casa um tanto de fazenda pra poder nos vestir, vestir as

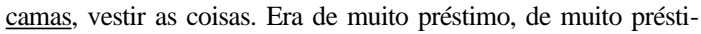
mo. Ela se criou sem mãe, mas era de muito préstimo, tanto cozinhar como costurar nossas roupas, as roupas de casa. Trabalhava, era de muito préstimo. Minha mãe, acho que tinha muito pouca pessoa que tinha energia como ela; a idéia também, porque muitas têm energia mas não tem idéia pra fazer nada. 
O ponto de referência de todas as famílias é a cidade de Passo Fundo sendo, ainda, a cidade onde residem a maioria dos membros dos quatro grandes grupos familiares. A seguir será apresentada a descrição de cada grupo geracional.

\section{Primeira Geração}

A geração que tem seu início por volta da segunda década deste século foi criada na colônia ${ }^{1}$, onde a principal atividade, e a mais valorizada, era a agricultura. Estas famílias caracterizavam-se como unidades de trabalho e de produção, constituindo-se no principal núcleo de convivência e cooperação. Sendo assim, os pais delegavam desde cedo responsabilidades e obrigações aos filhos, exigindo que fossem cumpridas indistintamente e com o máximo de empenho pessoal. Tanto as meninas quanto os meninos aprendiam a trabalhar na lavoura (roça), mas as meninas também deveriam ser responsáveis pelas lides domésticas e cuidado com os irmãos menores. O grupo tinha no trabalho familiar a prioridade para a formação dos filhos, elegendo o bem comum acima das necessidades e desejos pessoais.

A estrutura familiar dessa época era patriarcal. Isto é, o poder de decisão e os recursos financeiros estavam sob o controle do pai. Como autoridade maior, mantinha uma distância afetiva da mulher e dos filhos.

Com o pai a gente não respondia, e com a mãe sim... Com o pai não, era só a opinião dele que valia. [Primeira Geração da Família 3]

A mãe, por sua vez, correspondia às exigências sociais da época, desempenhando funções na organização doméstica e cuidado com os filhos. Não tinha tempo para dedicar-se a cada filho particularmente, pois, além da prole ser numerosa, o trabalho e a produtividade estavam acima da convivência familiar. Nesse contexto, a mulher utilizava a própria energia em prol do bem estar e melhoria da qualidade de vida do grupo. Seu principal papel era transmitir conhecimentos às filhas, pelo treinamento precoce de habilidades domésticas e de cuidado com as crianças. Essas tarefas deveriam ser desempenhadas com o máximo de perfeição e esforço. 
Minha mãe acho que tinha muito pouca pessoa que tinha energia como ela... Não tinha serviço que ela não fizesse. [Primeira Geração da Família 1]

Esse modelo familiar foi, em parte, reproduzido na vida adulta da primeira geração. A dignidade da mulher continua na capacidade de trabalhar e ajudar o marido na formação do patrimônio do casal. No entanto, já se pode constatar uma mudança importante na estrutura familiar: o casal demonstra um maior companheirismo e afinidade, tanto entre si quanto com os filhos.

A minha cabeça era mais ou menos como a [dos pais], mas meu marido tinha a cabeça mais aberta... O meu marido conversava bastante com os filhos... A gente era de acordo. Ele não tomava nenhuma decisão sem a minha aprovação. [Primeira Geração da Família 4]

Também na organização e dinâmica familiar verificam-se mudanças importantes entre a primeira geração e a anterior. A esposa começa a colaborar no orçamento familiar, participando indireta e discretamente nas decisões e deixando de ser completamente submissa ao marido. Ao discutir as decisões familiares com a mulher, o marido aproxima-se afetivamente da família, mantendo-se como autoridade máxima sem, contudo, ser aquela figura distante.

O pai era bastante autoritário, mas amigo; não era um autoritarismo que a gente dissesse que ele não era nosso amigo. [Segunda Geração da Família 1]

A mãe, contudo, continua limitando-se a delegar tarefas e obrigações rigorosamente supervisionadas, sendo a principal responsável pela socialização dos filhos. A organização familiar perpetua o modelo patriarcal da geração anterior com hierarquia e papéis bem demarcados. Aos pais cabia a responsabilidade de orientar os filhos sobre o melhor caminho. E, aos filhos, acatar tais orientações e obedecer aos pais que, por serem mais experientes, tinham autoridade para apontar o melhor. A educação dos filhos era tranqüila pois, conforme o costume da época, o comportamento infantil era disciplinado livre de influ- 
ências externas. Isto acontecia principalmente na colônia rural, onde a convivência era restrita ao grupo de parentes e vizinhos.

Era a família tal que ia visitar a família tal... e não os jovens que saíam pra se encontrar. [Segunda Geração da Família 2]

Contudo, a acelerada urbanização, que tem seu início por volta da década de 40, traz o casal para a cidade a fim de proporcionar melhores oportunidades de escolarização para os jovens. Gradativamente, a agricultura e produção familiar cedem lugar ao interesse por profissões liberais para os rapazes, e ao magistério para as moças. Desaparece, nesta geração, a cultura do mutirão familiar.

A gente vai pra cidade pras crianças estudarem porque aqui não vai dar nada; tem só umas escolinhas. [Primeira Geração da Família 4]

\section{Segunda Geração}

A segunda geração, iniciada por volta da década de 40, percebe sua mãe como uma mulher dinâmica e influente na família, na medida que dividia igualmente as responsabilidades pelo orçamento e sustento familiar, e pela socialização dos filhos. O pai, apesar de estar mais próximo dos filhos, continuava sendo a principal autoridade da casa.

O meu pai era muito exigente comigo, mas ele tinha uma relação mais afetuosa... Apesar de ele ser muito severo conosco, ele nunca bateu. A minha mãe batia. [Segunda Geração da Família 2]

Apesar de haver um ambiente familiar favorável à formação escolar e à profissionalização, não se descartava, em absoluto, a concomitante vida doméstica e de mãe de família. Sendo assim, a segunda geração preserva na vida adulta o lar e a família como prioritários, relegando a realização profissional para depois do crescimento dos filhos.

[A mãe] queria que a gente tivesse uma vida melhor, que a gente tivesse oportunidade de aprender as coisas que ela não pôde apren- 
der... Ela não tinha tido oportunidade, ela achava que seria bom que nós tivéssemos e valorizava bastante... Antes de eu casar eu trabalhei 8 anos. Depois eu fiquei 12 anos sem trabalhar, logo que nasceram os filhos... Depois eu voltei e fui fazer faculdade. [Segunda Geração da Família 1]

A partir do questionamento dessa geração sobre antigos comportamentos femininos, idéias e ações são reorganizadas na estrutura da família. O marido, mais participativo na educação dos filhos, fica exposto a críticas quando não corresponde às expectativas da família. Também, a possibilidade de planejamento familiar, pelo advento da pílula anticoncepcional, vem colaborar para a delimitação de espaços e identidades dentro do grupo. A partir do reconhecimento das diferenças individuais, inicia-se um questionamento e experimentação de formas alternativas na educação dos filhos.

Para a segunda geração, a educação dos filhos assume uma certa reciprocidade: não exigia obediência incondicional mas respeito às necessidades individuais e grupais. O carinho é considerado a recompensa pelo ajuste a ordens e determinações, implícitas ou explícitas.

[A mãe] dava um jeito de nos sentirmos culpados por não seguirmos as orientações que ela dava. Na verdade, não se pode dizer que ela cobrava ou impunha alguma coisa, mas ela chantageava emocionalmente aquele filho que não seguia as ordens que ela determinava. Não seriam bem ordens; seriam orientações, conselhos que, na verdade, eram ordens disfarçadas. [Terceira Geração da Família 2]

Os perigos externos eram as principais preocupações com os filhos pequenos e adolescentes. Isto se deve à vulnerabilidade da educação familiar, agora exposta à influência social no momento que permite questionar padrões herdados dos antepassados. A influência externa representa riscos desconhecidos para os pais da segunda geração em conseqüência, principalmente, da acelerada modernidade sócio-tecnológica. Diante da nova situação, as mães procuram não tolher a liberdade, controlando as experiências dos filhos de forma a protegê-los o máximo possível das adversidades.

Hoje em dia é muito difícil. O mundo oferece muitos perigos, muitas dificuldades que a gente não viveu. [Segunda Geração da Família 2] 


\section{Terceira Geração}

A terceira geração, iniciada por volta da década de 60, descreve sua criação como sendo tradicional. Teve uma educação muito controlada pelos pais que determinavam o melhor comportamento, através de vigilância e expectativas de adequação.

[Os pais] têm pontos de vista bem tradicionais em questões fundamentais como casamento, educação de filhos, religião... A nossa família é muito fechada, muito orgulhosa dela mesma. Nossos pais passavam a imagem de que nós éramos a família perfeita, de que nós, como filhos, estávamos todos nos encaminhando muito bem, que não haviam perturbados, que não havia nenhum desencaminhado. [Terceira Geração da Família 2]

A grande inovação na relação pais e filhos foi a possibilidade de diálogo, aumentando a proximidade afetiva. Tal prática contribuiu para o desenvolvimento de uma consciência crítica em relação aos pais e aos valores familiares. A terceira geração conquistou espaço próprio dentro do grupo familiar manifestando abertamente suas necessidades e crenças.

Com o pai estava tudo sempre bom. E [a mãe] não, achava que tem que estar tudo sempre super-organizado e arrumado. Então a gente sempre ficou entre esses dois extremos e até hoje existe conflito em função disso, dessas posturas diferentes... Para ela era difícil esse controle da vida familiar que ela, por sua vez, procurava fazer com o máximo de perfeição e, quando isso não acontecia, gerava um problema. [Terceira Geração da Família 1]

$\mathrm{Na}$ vida adulta, a terceira geração tem a organização familiar centrada nos filhos. Procura educá-los dentro de uma ideologia igualitária, na qual não existam papéis previamente estabelecido, e nem uma autoridade maior que deva ser acatada incondicionalmente. Não existe um referencial de conduta preestabelecido e sim a sensibilidade para avaliar o melhor comportamento nas diferentes ocasiões, geralmente procurando respeitar a liberdade de expressão e experimentação. $\mathrm{O}$ respeito às idiossincrasias e a empatia são princípios básicos no relacionamento familiar. 
Uma coisa importante é o próprio conhecimento que a gente tem; outra é o lado pessoal... E, pensando nisso, eu procuro não podar... Eu até procuro pensar como que é isso pra mim, como é que as outras pessoas fazem... Acho que [os filhos] vão ter que experimentar fazer as coisas e eu vou conversando, auxiliando, orientando. Eles têm liberdade pra me dizer as coisas, pra conversar, pra perguntar. [Terceira Geração da Família 3]

Contudo, a modernização social e o abandono aos padrões preestabelecidos de comportamento, relacionamento e valores, incrementa inseguranças e dúvidas. Diante disso, as mães recorrem a estratégias como ler, conversar com outras mães da mesma faixa etária, refletir e procurar entender o comportamento dos filhos e sua reação ao mesmo. A própria intuição também é utilizada, procurando prestar atenção no filho, nos seus desejos e necessidades. A intenção é formar adultos sem traumas, emocionalmente estáveis, socialmente adaptados e, principalmente, felizes.

Com relação à questão de educação, eu tenho 'n' inseguranças e dúvidas até hoje. Às vezes, de repente, não sei como eu respondo uma questão, como é que eu encaminho... Embora eu trabalhe, procure me conscientizar, procure pensar por onde andar. Mas sei lá. Os valores hoje em dia mudam muito e a gente não sabe se vai para a frente ou para trás. [Terceira Geração da Família 1]

\section{Redução Fenomenológica}

A descrição fenomenológica, situada na quase-localidade da linearidade geracional (referindo-se à perspectiva de leitura), desvelou modificações importantes na estrutura do grupo familiar. A tarefa de redução fenomenológica demarca as percepções que expressam os sentimentos de preservação da identidade familiar e da afirmação da diferença geracional. Essa tensão relacional pode ser entendida a partir de três categorias complementares: 1) transformações das regras de coesão e socialização familiar; 2) ampliação do espaço da mulher na vida familiar e profissional com a redefinição da função paterna; e 3) alterações nos valores educacionais. 
Transformações das regras de coesão e socialização familiar

A família de origem da primeira geração, enquanto poder patriarcal, valorizava o trabalho grupal. A capacidade produtiva da família era, para eles, decorrência imediata da força do trabalho e justificativa para a coesão grupal. A primeira geração, contudo, assumiu outra posição quanto à convivência familiar. A mudança do campo para a cidade fez com que, além da formação para o trabalho, a formação escolar fosse também priorizada. A escola proporcionou a capacitação individual e o respeito às necessidades e objetivos de cada membro do grupo. Em consequiência, diluiu o grupo familiar como força de produção grupal.

A segunda geração conservou respeito e deferência aos pais, principalmente ao pai, pela disciplina e obediência às normas de organização familiar. Todavia, o maior contato com a escola e com a vida urbana ampliou seus horizontes e apontou para novas possibilidades de organização social e convívio na família. Na educação dos filhos, acompanhou as mudanças sociais quanto à livre expressão, a valorização da afetividade e a integridade moral. Assim, a educação familiar baseava-se em noções explícitas de liberdade com responsabilidade.

A terceira geração substituiu os padrões da família por um sistema de referências particular, diferenciando-se significativamente das duas anteriores. Esta geração mostrou-se mais crítica, expressando posições de respeito à liberdade de escolha e opinião, e de estímulo à sensibilidade dos filhos. A formação para o trabalho perdeu em importância para a afetividade e autoconfiança e, principalmente, liberdade e autonomia para a realização pessoal, independentemente de planos preestabelecidos pelos pais. Efetivou-se a prática da compreensão e apoio familiar pelo respeito às necessidades individuais, bem como a preocupação com o ajustamento emocional e social dos filhos.

A socialização familiar, naturalmente, acompanhou as modificações contextuais. Os pais de primeira geração apresentaram uma forte herança cultural na preservação de crenças e práticas associadas à manutenção de valores familiares. Os pais da segunda geração, substituíram a rigidez relacional por uma forma de convivência familiar mais complacente e amistosa. Os pais da terceira geração modificaram com- 
pletamente o modelo relacional e assumiram uma postura crítica em relação à experiência familiar. Ademais, mostraram-se interessados em novos padrões e alternativas de educação e convivência com os filhos, e bastante independentes da herança parental. Apresentaram, enfim, um movimento de crítica e autocrítica tão intenso que negava completamente os referenciais familiares anteriores.

Ampliação do espaço da mulher na vida familiar $e$ profissional, e redefinição da função paterna

No contexto da primeira geração, onde a família era a unidade de trabalho e produção, a boa esposa era aquela que trabalhava arduamente com o marido para a formação do patrimônio do casal. A dignificação da mulher estava em sua disposição e habilidade para o trabalho braçal. A educação escolar das meninas não era valorizada. Elas se limitavam a escrever e ler o próprio nome, pois lhes era exigido que dominassem estritamente a esfera doméstica.

Acompanhando as transformações e mudanças dos tempos, a gratificação e afirmação da identidade feminina ampliou-se da esfera doméstica para novas e ambiciosas possibilidades profissionais. Essa ampliação do papel da mulher foi gradativa, acentuando-se a partir da segunda geração. Inicialmente era admitida desde que não prejudicasse seu desempenho no lar, que permanecia prioritário. Na terceira geração, todavia, já se apresentou como um leque de possibilidades, pois pode-se escolher entre a vida doméstica e profissional, combinar as duas, escolher entre casar ou permanecer solteira.

A função paterna, por sua vez, teve seu papel atualizado. A família rural de estrutura patriarcal, com autoridade centralizada, modificou-se na direção de uma família igualitária. A autoridade do pai passa a ser amistosa e, na última geração, vai se caracterizar como uma autoridade liberal amistosa. A autoridade do pai perde importância como postura inquestionável, ao mesmo tempo que os filhos adquirem mais autonomia e liberdade de opinião.

\section{Alterações nos valores educacionais}

As mudanças apareceram na comparação entre os valores recebidos e os que efetivamente se procurou transmitir para os filhos. A 
primeira geração foi ensinada a priorizar o trabalho doméstico e o casamento. A segunda, acrescenta ao trabalho doméstico e ao casamento uma nova prioridade: a formação escolar. Estas duas gerações, no entanto, preservam o sentido de família como unidade de cooperação e crescimento pessoal, tendo o pai como figura central a quem se deveria respeito e obediência, e a mãe como única responsável pelos afazeres domésticos e socialização dos filhos. Acontece que a formação escolar levou a uma consciência de profissionalização feminina, abrindo novas possibilidades de gratificação, afirmação e de identidade pessoal pela independência financeira. Eé, justamente, a independência financeira o valor prioritário que a terceira geração adotou como forma de afirmação da identidade da mulher moderna. Os sentimentos de independência da terceira geração expressaram-se na relação familiar através do respeito às idiossincrasias dos filhos. Esta geração não mais pressiona os filhos para seguirem uma ou outra carreira e serem profissionais de sucesso. Os filhos são estimulados a procurarem os próprios meios de alcançar a felicidade, contando sempre com o apoio e compreensão dos pais, pela valorização da afetividade.

\section{Interpretação Fenomenológica}

A síntese descritiva ofereceu uma explanação das modificações da estrutura familiar associada a um movimento sinérgico do sentido essencial de cada geração. O movimento sinérgico refere-se, naturalmente, ao encadeamento transformador na sucessão geracional, no qual transformações produzem novas transformações. O encadeamento é sinérgico porque uma transformação produz uma outra maior, no sentido de abertura, possibilidade e efetivação.

A síntese redutiva, por sua vez, especificou a redefinição de sentido familiar nas regras de coesão, pela demarcação das percepções de preservação de identidade familiar e afirmação da diferença geracional.

A interpretação será uma articulação dos temas apresentados na descrição e demarcados na redução em termos de contrastes entre presenças - o que está baseado no depoimento dos informantes e na literatura; e ausências - o que está baseado na intuição contextual do pesquisador. Serão privilegiados dois grandes temas. Primeiro, a função de estudos correlatos enquanto possibilidade confirmatória e ex- 
tensível de estudos qualitativos. Segundo, recorrendo novamente à suspensão fenomenológica, despreza-se considerações sobre os demais temas para concentrar-se, ainda que brevemente, nos relatos da Terceira Geração sobre a situação de "não referência" na educação dos filhos.

\section{Possibilidade confirmatório e extensivel do capta}

Este estudo interpreta que a descrição geracional de famílias de classe média, residentes na região da Cidade de Passo Fundo - RS, exemplifica as transformações ocorridas na família brasileira nos últimos 80 anos e pode ser reconhecida como uma confirmação de achados e interpretações de estudos anteriores. Interpretações, neste sentido, apareceram em vários estudos brasileiros que trataram de temas como redimensionamento da autoridade, da hierarquia e da complementaridade de papéis familiares (Bezerra de Menezes, 1983; Nicolaci-da-Costa, 1987, 1988; Nogueira, 1988; Prado, 1982; Romanelli, 1988). As transformações nas regras de convivência e socialização se deram, naturalmente, por exigências da modernidade sócio-tecnológica e das acomodações ao novo contexto social. Na sucessão geracional, é importante considerar que a qualidade comunicativo-relacional desvela, em cada família, a sensibilidade para perceber a necessidade e a possibilidade de mudança. Neste eixo entre necessidade e possibilidade situa-se ou a resistência ou a aceitação à mudança. Contudo, tal relação não é necessariamente excludente (binária). Ela agrega um conjunto de possibilidades combinatórias (analógicas) na qual resistência e aceitação interagem em múltiplas formas e em intensidades diversas.

A mudança do espaço de gratificação e afirmação da identidade feminina apareceu, neste estudo, relacionada às expectativas das mães da primeira geração quanto ao futuro profissional das filhas. Romanelli (1988) chegou a essa mesma compreensão estudando mulheres paulistas. Segundo ele, as mães da primeira geração incentivaram as filhas a assumirem uma posição inovadora na família. A participação da mulher no mercado de trabalho mostrou-se subordinada à ação socializadora da mãe. $O$ redimensionamento dos papéis de gênero na família e as consequiências do processo de profissionalização femini- 
na foram descritos por muitos autores brasileiros (Bezerra de Menezes, 1983; Nogueira, 1988; Santos, 1988; Teixeira, 1994). Em conseqüência dessas mudanças, a democratização da família foi interpretado como um padrão adaptativo de funcionamento parental diante de variações situacionais (Bastos,1991; Biasoli Alves, Caldana \& Dias da Silva,1988).

A maturidade foi um fator presente na concepção de família e na percepção da relação com os ascendentes e descendentes. As gerações mencionaram recorrentemente que o passar da idade e a vivência de experiências semelhantes facilitam a compreensão e aceitação das demais gerações. A mediação do processo maturacional na qualidade do relacionamento familiar é um consenso na literatura (Bengtson \& Kuypers, 1971; Fisher \& Johnson, 1990). A forma e o significado da relação evolui com a maturidade e experiências, criando novas identidades e arranjos, e extinguindo outros já inadequados. Isso significa que padrões de relacionamento geracional não são refratários a mudanças cronológicas e maturacionais

As relações intergeracionais mostraram-se organizadas por duas forças antagônicas: a da descontinuidade, no sentido da promoção de padrões alternativos e da modernidade social; e a da continuidade, no sentido de promoção da linearidade familiar. A continuidade ou linearidade revela-se no processo de coesão. O conceito de coesão é definido como o grau de interação entre as pessoas que se reflete na mutualidade de atividades, interesses e idéias. Deste modo, tende a neutralizar as diferenças inerentes na sucessão linear, promovendo a união e continuidade da família através dos anos (Feldman \& Gehring, 1990). Por outro lado, a família exerce um controle menos efetivo sobre determinadas idéias e comportamentos que estão sujeitos à habilidade individual e forças externas, tais como ocupação profissional e educação formal (Ackerman, 1986) .

O papel do gênero na linearidade familiar foi um viés apriorístico desta pesquisa, no sentido de captar a intimidade e compreensão compartilhadas entre mulheres de três gerações. Na mesma linha de entendimento, estão os trabalhos de Aldous e Hill (1965) e Roberts e Bengtson (1990). No Brasil, Bernardes (1993) interpretou que as diferenças homem/mulher implicam não somente em estruturas biológicas mas na própria gênese das estruturas psicológicas que constitu- 
em os processos de simbolização, envolvendo as relações adulto/ criança e os imperativos culturais.

O relacionamento problemático entre gerações não é privilégio somente da novíssima geração com os mais velhos. É certo que, partindo da perspectiva da psicologia do desenvolvimento, o conflito intergeracional é uma etapa do processo de auto-diferenciação e libertação da autoridade dos pais (Elkind, 1970). Porém, é importante ter em mente que o conflito geracional está presente em todas as fases do desenvolvimento do indivíduo, mesmo quando alcança a maturidade e habilidade de compreensão e elaboração, tal como apareceu neste trabalho.

A primeira síntese interpretativa revelou importantes fatores que interferem nas permutas intergeracionais e intrageracionais no processo sucessivo, a saber: 1) desenvolvimento sócio-cognitivo; 2) gênero; e 3) proximidade física e/ou psicológica. O desenvolvimento sócio-cognitivo reflete o estágio de julgamento crítico e auto-reflexivo que promove a continuidade ou descontinuidade, regula as contestações, e contribui para a aquisição e afirmação da identidade familiar. $\mathrm{O}$ gênero, revelado nas práticas de maternagem, tende a aproximar as gerações favorecendo a mutualidade de experiências e informações. Por fim, a aproximação física ou psicológica entre pais e filhos favorece a mutualidade da vigilância e das críticas na elaboração do conflito inerente às relações lineares. Em suma, a relação intergeracional configurou-se pautada por esses fatores que ora funcionam como facilitadores, ora como obstáculos no processo de sucessão geracional. Desta forma, a contextualização da síntese interpretativa na literatura mostrou que estas famílias gaúchas apresentam, em muitos aspectos, as mesmas vicissitudes de famílias estudadas em outras partes do país. Esta constatação reafirma a possibilidade de transferibilidade de tomados (capta) qualitativos.

\section{A "não-referência” na educação dos filhos}

A substituição de valores familiares, que ocasionou uma crise nos padrões educacionais, especialmente na terceira geração dessa tríade de mães, estende-se, do mesmo modo, a outras regiões do país. A atual geração de pais vive numa fase de transição: ao mesmo tempo em que tem consciência do que não deve fazer, ainda não encontrou 
um padrão adequado de comportamento para passar aos filhos. Resultados semelhantes foram encontrados em uma pesquisa na Cidade do Rio de Janeiro e foi interpretado com ausência de um sistema único de valores em uma sociedade intensamente dinâmica e pluralista (Zagury, 1991). Sobre o mesmo fenômeno, Bezerra de Menezes (1983) investigando pais da classe média de Fortaleza, concluiu que as noções de certo e errado foram perdendo a clareza e o significado na educação familiar, com a recusa aos padrões anteriores e a adoção da pluralidade de escolhas. Ressalte-se que as mudanças nos padrões educacionais e da imagem infantil acompanhando a modernidade social não ocorreram somente no Brasil. Segundo Lasch (1991), também nos Estados Unidos e, de maneira mais ampla, na cultura ocidental existe uma crise generalizada nos padrões educacionais em função de uma nova concepção de infância, segundo a qual a criança é considerada em sua fase de desenvolvimento como uma pessoa com atributos característicos (suceptibilidade, vulnerabilidade, inocência). Interpreta-se que a contundência destes achados e tomados exigem atenção dos pesquisadores, tanto no sentido de ampliar e pormenorizar estas descrições quanto propor modos de orientação e auxílio para mães e pais. Uma sociedade como a brasileira, no particular momento histórico que atravessa, oferece condições de especial interesse para o estudo das relações familiares e dos processos de transmissão cultural. Um programa sistemático e continuado de pesquisa sobre relações familiares, com núcleos de trabalho em diversas regiões brasileiras é não somente desejável mas, sobretudo, necessário.

\section{Referências}

Ackerman, N. W. (1986). Diagnóstico e tratamento das relações familiares. Porto Alegre: Artes Médicas.

Acock, A. C., \& Bengtson, V. L. (1980). Socialization and attribution processes: Actual versus perceived similarity among parents and youth. Journal of Marriage and the Family, 42, 501-515.

Aldous, J. (1978). Familiy careers: Developmental change in families. New York: John Wiley \& Sons.

Aldous, J., \& Hill, R. (1965). Social cohesion, lineage type, and intergenerational transmission. Social Forces, 43, 471-482. 
Almeida, M. I. M. de (1987). Maternidade: Um destino inevitável? Rio de Janeiro: Campus.

Altheide, D. L., \& Johnson, J. M. (1994). Criteria for assessing interpretative validity in qualitative research. In N. K. Denzin \& Y. S. Lincoln (Orgs.), Handbook of qualitative research (pp. 485499). Thousand Oaks, California: Sage.

Andolfi, M. (1989). Crise de casal e família trigeracional. Revista Brasileira de Pesquisa em Psicologia, 1(2), 48-50.

Bastos, A. C. S. (1991). Idéias sobre a criação de filhos: Uma invenção cultural. Psico, 22(2), 63-87.

Bengtson, V. L. (Ed.). (1996). Adulthood and aging: Research on continuities and discontinuities. New York: Springer Publishing.

Bengtson, V., \& Kuypers, J. A. (1971). Generational difference and developmental stake. Aging and Human Development, 2, 249-60.

Benoit, D., \& Parker, K. C. H. (1994). Stability and transmission of attachment across three generations. Child Development, 65, 1444-1456.

Bernardes, N. M. G. (1993). Autonomia/submissão do sujeito e identidade de gênero. Cadernos de Pesquisa, 85, 43-53.

Bezerra de Menezes, M. I. C. B. (1983). Crise e futuro da família. Revista de Psicologia, 1(1), 83-105.

Biasoli Alves, Z. M. M., Caldana, R. H. L., \& Dias da Silva, M. H. G. F. (1988). Famílias e práticas de educação da criança e do adolescente. Em Sociedade Brasileira de Psicologia (Org.), Resumos da XVIII Reunião Anual de Psicologia, p. 95.

Cashmore, J. A., \& Goodnow, J. (1985). Agreement between generations: A two-process approach. Child Development, 56, 493-501.

Clebone, B., L., \& Taylor, C., M. (1992). Family and social attitudes across four generations of women or maternal lineage. Psychological Reports, 70, 268-270.

Covell, K., Grusec, J., \& King, G. (1995). The intergenerational transmission of matermal discipline and standards for behavior. Social Development, 4(1), 32-43.

Diamond, D., \& Doane, J. A. (1994). Disturbed attachment and negative affective style: An intergenerational spiral. British Journal of Psychiatry, 164, 770-781.

Dias da Silva, M. H. G. F., \& Biasoli Alves, Z. M. M. (1987a). A procura e orientação na educação dos filhos: Da sabedoria popular ao cientificismo. Ciência e Cultura, 39(7, suplemento), 878.

Dias da Silva, M. H. G. F., \& Biasoli Alves, Z. M. M. (1987b). O ideário da educação dos filhos pequenos: Alterações em 50 anos. Ciência e Cultura, 39 (7, suplemento), 879. 
Doumas, D., Margolin, G., \& John, R. (1994). The intergenerational transmission of agression across three generations. Journal of Family Violence, 9(2), 157-175.

Elder, G. H., King, V., \& Conger, R. D. (1996). Intergenerational continuity and change in rural lives: Historical and developmental insights. International Journal of Behavioral Development, 19(2), 433-455.

Elkind, D. (1970). Exploitation and generational conflict. Mental Hygiene, 54, 490-497.

Feldman, S. S., \& Gehring, T. M. (1990). Changing perceptions of family cohesion and power across adolescence. In R. E. Muuss (Org.), Adolescent behavior and society: A book of readings (pp. 130142). New York: McGraw-Hill.

Ferro-Bucher, J. S. N. (1986). Mitos, segredos e ritos na família II: Uma perspectiva intergeracional. Psicologia: Teoria e Pesquisa, 2(1), 14-22.

Figueira, S. A. (1987). O "moderno" e o "arcaico" na nova família brasileira: Notas sobre a dimensão invisível da mudança social. In S. A. Figueira (Org.), Uma nova familia? O moderno e o arcaico na família de classe média brasileira, (pp. 11-30). Rio de Janeiro: Zahar.

Figueira, S. A. Nos bastidores da psicanálise: Sobre politica, história, estrutura e dinâmica do campo psicanalítico. Rio de Janeiro: Imago.

Fisher, C. B., \& Johnson, B.L. (1990). Getting mad at mom and dad: Children's changing views of familiy conflict. International Journal of Behavioral Development, 13, 31-48.

Giorgi, A. (1985). Sketch of a psychological phenomenological method. In A.Giorgi (Org.), Phenomenology and Psychological Research, (pp. 8-22). Pittsburgh: Duquesne University Press.

Gomes, W. B. (1987). As aplicações sociais da pesquisa qualitativa. Psicologia: Reflexão e Crítica, 2, 3-12.

Guardo, C. J. (1982). Student generations and value change. The Personnel and Guidance Journal, 60, 500-503.

Jacobvitz, D. B., Morgan, E., Kretchman, M. D., \& Morgan, Y. (1991) The transmission of mother-child boundary disturbances across three generations. Special Issue: Attachment and developmental psychopathology. Development and Psychopathology, 3. 513-527.

Jenning, M. K., \& Niemi, R. G. (1968). The transmission of political values from parent to child. The American Political Science Review, 62, 169-184.

Lanigan, R. (1988). Phenomenology of communication. Pittsburg, PA: Duquesne University Press. 
Lasch, C. (1991). Refúgio num mundo sem coração. A família: Santuário ou instituição sitiada? Rio de Janeiro: Paz e Terra.

Laufer, R. S., \& Bengtson, V. L. (1974). Generations, aging, and social stratification: On the development of generational units. Journal of Social Issues, 30, 181-205.

Leiden, U. (1992). Intergenerational transmission of parenting: A review of studies in nonclinical populations.Developmental Review, 12(1), 76-99.

Lins de Barros, M. (1987). Autoridade e afeto: Avós, filhos e netos na família brasileira. Rio de Janeiro: Zahar.

Nicolaci-da-Costa, A.M. (1987). Sujeito e cotidiano: Um estudo da dimensão psicológica do Social. Rio de Janeiro: Campus.

Nicolaci da Costa, A.M. (1988). O processo de modernização da sociedade e seus efeitos sobre a família contemporânea. Em Sociedade Brasileira da Psicologia (Org.), Anais da XVIII Reunião Anual de Psicologia, pp. 101-107.

Nogueira, C.B. (1988). Individualidade - reprodução - família (o conflito vivido pela mulher de hoje). Psicologia e Sociedade, 5, 124-140.

Morse, J. M. (1994). Designing founded qualitative research. In N. K. Denzin \& Y. S. Lincoln (Orgs.), Handbook of qualitative research (pp. 220-235). Thousand Oaks, California: Sage.

Patton, M. Q. (1990). Qualitative Evaluation Methods. Beverly Hills: Sage.

Prado, D. (1982). O que é família? São Paulo: Brasiliense.

Roberts, R. E. L., \& Bengtson, V. L. (1990). Is intergenerational solidarity a unidimensional construct? A second test of a formal model. Journal of Gerontology, 45(1), 12-20.

Rogers, S. J., Parcel, T. L., \& Menaghn, E. G. (1991). The effects of maternal working conditions and mastery on child behavior problems: Studying the intergenerational transmission of social control. Journal of Health and Social Behavior, 32(2), 145-164.

Romanelli, G. (1988). Famílias de camadas médias: Modernidade e mudança. Em Sociedade Brasileira de Psicologia (Org.), Anais da XVIII Reunião Anual de Psicologia, pp. 75-82.

Rosenthal, D. A. (1984). Intergenerational conflict and culture: A study of immigrant and nonimmigrant adolescents and their parents. Genetic Psychology Monographs, 109, 53-75.

Samara, E. M. (1986). A Familia brasileira. São Paulo: Brasiliense.

Santos, T. C. (1988). A mulher liberada e a difusão da psicanálise. In S. A. Figueira (Org.), Efeito Psi - A Influência da psicanálise, (pp. 103-119). Rio de Janeiro: Campus.

Spiegelberg, H. (1982). The Phenomenological movement (3rd ed.rev., 2 vols.) The Hague: Martinus Nijhoff. 
Teixeira, M. L. P. (1994, 9 de janeiro). O fim da mulher romântica.Zero Hora, 5-8.

Thomas, L. E. (1974). Generational discontinuity in beliefs: An exploration of the Generation Gap. Journal of Social Issues, 30, 122.

Tolor, A. (1976). The generation gap: Fact or fiction? Genetic Psychology Monographs, 94, 35-130.

Velho, G. (1981). Individualismo e cultura. Rio de Janeiro: Zahar.

Velho, G. (1989). Subjetividade e sociedade: Uma experiência de geração. Rio de Janeiro: Zahar.

Williamson, D. S., \& Bray, J. H. (1991). El desarrolo y cambio familiares através de las generations: Una perspectiva intergenerational. In C. J. Falicov (Org), Transiciones de la familia: Continuidad y cambio en el ciclo de vida (pp. 491-527). Buenos Aires: Amorrortu.

Zagury, T. (1991). Sem padecer no paraíso - em defesa dos pais ou sobre a tirania dos filhos. Rio de Janeiro: Record. 
Anexo A - Roteiro de Entrevista

1) Família de origem: os pais, a infância, a juventude.

- Desde quando vive nesta região?

- Onde e quando nasceu?

- Característica dos pais (etnia, religião, atividades profissionais, situação econômica).

- Quantos irmãos tem?

- Como era o relacionamento com o pai? Como era o relacionamento com a mãe?

- Como era o relacionamento com os irmãos?

- Algum outro parente morava na casa?

- Como foi a experiência escolar?

- Alguém marcou especialmente na infância? E na juventude?

- Relacionamento com rapazes na época. Como foi a escolha definitiva?

2) Vivência da maternidade: a experiência de ser mãe.

- Desejos, planos, expectativas maternais.

- Como foi se configurando a família (configuração familiar)?

- Quais os sentimentos decorrentes do fato de ser mãe?

- Em relação a ser mãe, o que foi mais difícil?

- Ser mãe é algo que vem naturalmente?

3) A família nuclear: o relacionamento com os filhos pequenos; o papel do marido; as preocupações na educação dos filhos; o relacionamento com os filhos adultos; valores e objetivos na educação dos filhos

- Como a convivência foi se transformando com o crescimento dos filhos?

- Quando eles eram bem pequenos, como "se virava" para dar conta? Como era o pai nesta época?

- Quando eles começaram a ir para a escola, o que foi mudando na sua relação com eles, qual era a influência sobre eles, quais eram as preocupações? E o pai nesta época.

- Quando foram ficando mocinhos, o que acontecia na relação com a mãe e com o pai, e as preocupações da época? Como era a convivência com o grupo de amigos e as preocupações? Em que ouviam os amigos e o que pesava mais?

- Quando ficaram adultos, como foi as relações de namoro, escolha profissional, afastamentos, viagens? Como foi a saída de casa, e as preocupações?

- Qual a fase de maior preocupação? Qual a fase que o relacionamento foi mais difícil?

- O que é ser uma boa mãe?

- Como são as relações atualmente, conversas, consultas, diferenças entre filhos, concordâncias e discordâncias?

- Em que aspectos gostaria que os filhos fossem parecidas e em que aspectos tu gostarias que fossem diferentes?

- E como os descreve atualmente?

- Quando se sente mais próxima dos filhos (ou mais distante)?

- Que valores e lições acredita (ou que espera passar) ter passado para os seus filhos?

- Que valores e lições reconhece que a mãe passou?

- Como é a relação atual com ela?

- Como caracteriza hoje a mãe - no que são parecidas, e no que são diferentes? 
4) Descrição do convívio atual da grande família (quando, quanto, onde, o que conversam, o que gostam, o que não gostam e como gostaria que fosse).

- O que é possível observar nas relações entre as diferentes faixas de idade?

- Comparação entre a família atual e a família de então (explorar diferentes momentos na família através dos tempos).

5) Perguntas complementares.

- Tempo de casamento; profissão do marido e da mulher; idade de ambos; número de filhos e distância entre eles, etc.

William B. Gomes é Doutor,

Sobre os autores

professor no Instituto de Psicologia da Universidade Federal do Rio Grande do Sul. Endereço para correspondência: Instituto de Psicologia - UFRGS, Rua Ramiro Barcelos 2600/119, CEP 90035.003, Porto Alegre - RS, Tel. (051) 3165115; 3165246, 3309507. Fax (051) 3304797, e-mail: gomes@ vortex.ufrgs.br. Ciomara Ribeiro S. Benicá é doutoranda em Psicologia do Desenvolvimento da UFRGS e professora no Departamento de Psicologia da Universidade de Passo Fundo - RS. 